\title{
ANALISIS KESALAHAN MAHASISWA DALAM PERKULIAHAN MATEMATIKA DASAR SECARA DARING
}

\author{
Wilmintjie Mataheru $^{*}$, Novalin C Huwaa ${ }^{2}$, Christi Matitaputty ${ }^{3}$ \\ 1,2,3Program Studi Pendidikan Matematika, Pascasajana, Universitas Pattimura \\ Jalan Ir. Putuhena, Kampus Unpatti, Poka, Ambon, Indonesia \\ e-mail: ${ }^{1}$ wilmintjiemataheru @yahoo.co.id; \\ Submitted: April 24, 2021 \\ Revised: May 14, 2021 \\ Accepted: May 16, 2021 \\ corresponding author*
}

\begin{abstract}
Abstrak
Topik matematika dasar merupakan fokus utama saat mempersiapkan mahasiswa baru masuk sebelum masuk perkuliahan di jenjang perguruan tinggi. Oleh karena itu, mahasiswa harus dapat memahami konsep dari beberapa topik matematika dasar ini dengan baik. Tujuan penelitian ini adalah untuk mendeskrpsikan kesalahan-kesalahan dalam memahami topik-topik matematika dasar, yaitu topik himpunan, relasi, fungsi, matriks, vektor, limit, turunan dan integral. Penelitian ini menggunakan metode penelitian deskriptif kualitif dengan subjek penelitian adalah mahasiswa baru tahun akademik 2020/2021 pada Program Studi Pendidikan Matematika FKIP Unpatti. Instrumen dalam penelitian ini berupa soal tes yang terdiri dari 7 soal tentang topik-topik matematika dasar. Hasil penelitian menunjukkan bahwa mahasiswa melakukan beberapa kesalahan di antaranya kesalahan faktual, kesalahan prosedural, kesalahan konseptual dan kecerobohan.
\end{abstract}

Kata Kunci: kesalahan mahasiwa, deskriptif kualitatif, matematika dasar

\section{ANALYSIS OF STUDENT ERRORS OF ONLINE BASIC MATHEMATICS COURSE}

\begin{abstract}
Basic mathematics topics are the main focus when preparing new students to enter before entering lectures at the tertiary level. Therefore, students must be able to understand the concepts of some of these basic math topics well. The purpose of this study was to describe the errors in understanding the course topics, namely sets, relations, functions, matrices, vectors, limits, derivatives, and integrals. This study used a qualitative descriptive research method with the research subjects being new students in the academic year 2020/2021 in the Mathematics Education Study Program, FKIP Unpatti. The instrument in this study was a test item consisting of 7 questions on basic mathematics topics. The results showed that students made several mistakes, including factual errors, procedural errors, conceptual errors, and careless errors due.
\end{abstract}

Kata Kunci: student's errors, qualitative descriptive, basic mathematics

\section{Pendahuluan}

Kegiatan matrikulasi merupakan salah satu kegiatan wajib yang harus diikuti oleh mahasiswa baru sebelum masuk perkuliahan semester pertama pada Program studi Pendidikan Matematika FKIP Unpatti. Kegiatan ini bertujuan untuk menjamin kemampuan dan penguasaan mahasiswa terhadap materi prasyarat, sehingga dapat mendukung keberhasilan proses belajar mengajar (Ratumanan \& Laurens, 2016). Jika mahasiswa memiliki kemampuan terhadap materi matematika dasar yang baik maka akan meningkatkan kemampuan penguasaan konsep dan hasil belajar (Nurhikmayati, 2017). Dengan demikian penting bagi mahasiswa untuk menguasai materi matematika dasar dalam kegiatan matrikulasi.

Kenyataan menujukkan bahwa mahasiswa Program Studi Pendidikan Matematika FKIP Unpatti memiliki penguasan konsep matematika dasar yang rendah (Mataheru, 2019). Hal ini didukung oleh penelitan (Ratumanan \& Laurens, 2016) yang melaporkan bahwa penguasaan konsep matematika mahasiswa baru/lulusan SMA Provinsi Maluku dikategorikan sangat rendah. Senada

Copyright (C) Authors. This is an open access article distributed under the Attribution-NonCommercialShareAlike 4.0 International (CC BY-NC-SA 4.0), which permits unrestricted use, distribution, and reproduction in any medium, provided the original work is properly cited. 
dengan hal ini, Subanji dan Nusantara (2013) menyatakan bahwa kesulitan dalam memahami konsep merupakan salah satu kesulitan yang dialami saat mengonstruksi dan memecahkan masalah matematika. Kesulitan siswa memahami konsep dapat menyebabkan terjadinya kesalahan konsep, prosedur maupun algoritma (Kesumawati, 2008). Saat menyelesaikan masalah matematika, tidak jarang ditemui siswa melakukan kesalahan dalam memahami konsep matematika.

Menurut Hasim (2020) tuntutan kurikulum Merdeka Belajar mengharuskan peserta didik tidak saja memenuhi kemampuan literasi tetapi juga kemampuan numerasi. Literasi dan numerasi menekankan pada pemahaman konsep dan penerapan konsep dalam kehidupan nyata. Selanjutnya, Zulkardi (2003) menyatakan bahwa salah satu ciri dalam pembelajaran matematika adalah memberi penekanan pada konsep, sehingga pemahaman konsep membantu siswa mengaplikasikan matematika dalam kehidupan sehari-hari. Utari \& Utami (2019) mengatakan, pemahaman konsep menjadi penting dimiliki oleh mahasiswa sebelum menyelesaikan suatu pemasalahan matematika.

Topik matematika dasar merupakan fokus utama saat mempersiapkan mahasiswa baru sebelum mengikuti perkuliahan di jenjang perguruan tinggi. Oleh karena itu, mahasiswa harus dapat memahami konsep dari beberapa topik matematika dasar ini dengan baik. Namun, kenyataan di lapangan menunjukkan bahwa berdasarkan pengalaman peneliti $(\mathrm{NH})$ menyatakan bahwa dalam mengajar mata kuliah Pengantar Dasar Matematika secara daring, terdapat mahasiswa yang selalu merasa kesulitan dalam memahami materi himpunan, relasi dan fungsi. Kesulitan tersebut diakibatkan, karena kesalahan memahami konsep, membedakan contoh dan bukan contoh. Sementara itu pengalaman mengajar kedua peneliti lainnya (WM dan CM) pada mata kuliah Kajian Matematika SMA menyatakan bahwa di antara beberapa topik kajian matematika SMA seperti matriks, vektor, limit, turunan dan integral merupakan topik yang dianggap sulit dan mahasiswa banyak melakukan kesalahan, karena kurangnya pengetahuan konseptual dan prosedural dalam memahami topiktopik tersebut

Brown dan Skow (2016) mendeskripsikan empat kesalahan yang dialami siswa dalam menyelesaikan masalah matematika, yaitu kesalahan konsep, kesalahan fakta, kesalahan prosedur, dan kesalahan karena kecerobohan. Kesalahan fakta adalah kesalahan yang terjadi, karena kurangnya informasi faktual. Kesalahan prosedural adalah kesalahan, karena pelaksanaan langkah-langkah dalam proses matematika. Kesalahan konseptual adalah kesalahan, karena kesalahpahaman atau kesalahan pemahaman yang mendasari prinsip dan ide yang terkait dengan masalah matematika dan kesalahan karena keceroboh atau kurang teliti dalam menyelesaikan masalah matematika. Keempat kesalahan ini dapat terjadi, karena kurangnya penguasaan materi matematika, minimnya keterampilan memahami bacaan, dan kurangnya kemampuan dalam menyatakan informasi ke dalam persamaan matematika. Akan tetapi, kesalahan yang dialamai oleh mahasiswa tidak berarti memberikan jastifikasi negatif terhadap kelemahan mahasiswa tersebut, namun hal ini dapat digunakan untuk mencari alternatif solusi. Selain itu, Kapur (2014) mengatakan bahwa kegagalan mahasiswa dapat menjadi pengalaman untuk belajar dari kesalahan dan menjadi lebih baik dalam menyelesaikan masalah matematika.

Dalam penelitian ini, materi pokok matematika dasar yang diajarkan selama kegiatan matrikulasi mahasiswa baru, yaitu materi Himpunan, Relasi, Fungsi, Limit, Turuanan dan Integral. Penelitian ini difokuskan untuk menganalisis kesalahan yang dibuat mahasiswa terkait topik-topik tersebut. Berdasarkan analisis kesalahan ini maka diharapakan dapat ditemukan faktor-faktor penyebab dan solusinya, agar dapat meminimalkan kesalahan pemahaman konsep matematika mahasiswa, sehingga mahasiswa lebih siap dengan pembelajaran selanjutnya pada jenjang perguruan tinggi.

\section{Metode Penelitian}

Penelitian ini menggunakan metode penelitian kualitatif deskriptif dengan tujuan mendeskripsikan miskonsepsi mahasiswa baru dalam menyelesaikan masalah matematika dasar. Subjek dalam penelitian ini sebanyak 41 mahasiswa yang mengikuti kegiatan matrikulasi pada tahun akademik 2020/2021. Data dalam penelitian ini dikumpulkan melalui hasil pekerjaan mahasiswa dalam menyelesaikan soal matematika dasar. Data ini digunakan untuk menganalisis kesalahan-kesalahan mahasiswa dalam menyelesaikan soal berdasarkan indikator kesalahan pada tabel 1. Tahapan dalam penelitian ini meliputi reading, describing dan classifying (Mills \& Gay, 2019). Pada tahap reading, peneliti menelaah jawaban tertulis mahasiswa untuk mengidentifikasi pola kesalahan yang dilakukannya. Selanjutnya pada tahap describing, peneliti mendeskripiskan kesalahan yang paling 
sering dilakukan mahasiswa berdasarkan 4 tipe kesalahan, yaitu kesalahan faktual, konseptual, prosedural dan kesalahan karena kecerobohan (Brown \& Skow, 2016). Pada tahap classifying, peneliti mengelompokkan jawaban mahasiswa berdasarkan indikator dari setiap jenis kesalahan.

\section{Hasil dan Pembahasan}

Berdasarkan hasil analisis data, peneliti mengklasifikasikan jawaban mahasiswa dalam 4 tipe kesalahan dan menentukan indicator untuk setiap tipe kesalahan dalam menyelesaikan masalah. Peneliti melakukan analisis kesalahan terhadap semua topik yang diberikan dalam kegiatan matrikulasi, namun dalam makalah ini peneliti hanya memberikan deskripsi kesalahan mahasiswa dari beberapa materi terkait dengan indikator kesalahan yang dirumuskan. Jenis kesalahan dan jumlah kesalahan yang dilakukan mahasiswa ditunjukkan pada Tabel 1 .

Tabel 1. Jumlah Tipe Kesalahan Mahasiswa dalam Menyelesaikan Masalah Matematika Dasar

\begin{tabular}{|c|c|c|c|}
\hline Tipe Kesalahan & Indikator & $\begin{array}{c}\text { Jumlah } \\
\text { Kesalahan }\end{array}$ & Kode \\
\hline A. Kesalahan Fakta & $\begin{array}{l}\text { Tidak memahami simbol-simbol yang terdapat } \\
\text { pada definisi }\end{array}$ & 31 & A1 \\
\hline \multirow[t]{2}{*}{ B. Kesalahan Konseptual } & $\begin{array}{l}\text { 1. Kesalahan memahami gagasan dan } \\
\text { prinsip dasar dari suatu konsep }\end{array}$ & 78 & B1 \\
\hline & $\begin{array}{l}\text { 2. Kesalahan memahami hubungan antara } \\
\text { ide dan prinsip }\end{array}$ & 72 & B2 \\
\hline \multirow[t]{2}{*}{ C. Kesalahan Prosedural } & $\begin{array}{l}\text { 1. Kesalahan menerapkan aturan atau } \\
\text { algoritma/ rumus atau langkah demi } \\
\text { langkah }\end{array}$ & 53 & $\mathrm{C} 1$ \\
\hline & 2. Melakukan operasi yang salah & 65 & $\mathrm{C} 2$ \\
\hline \multirow[t]{2}{*}{ D. Kesalahan kecerobohan } & 1. Salah memilih stategi/ kurang teliti & 23 & D1 \\
\hline & $\begin{array}{l}\text { 2. Merasa kurang waktu dalam mengerjakan } \\
\text { soal }\end{array}$ & 121 & D2 \\
\hline
\end{tabular}

Tipe kesalahan A1 merupakan kesalahan factual, yaitu kesalahan yang terjadi saat mahasiswa tidak mengetahui istilah matematika, misalnya kurang memahami beberapa kosa kata atau definisi dari topik Relasi dan Fungsi. Selain tu terdapat 2 kesalahan, yaitu kesalahan dalam memahami definisi relasi "faktor dari" pada suatu himpunan, dan kesalahan dalam memahami definisi relasi ekuivalen. Menurut peneliti, penyebab kesalahan mahasiswa ini terjadi, karena pemahaman yang lemah tentang definisi relasi dan bagaimana menyatakan sebuah relasi. Selain itu, mahasiswa belum dapat menyatakan secara jelas suatu relasi yang ekuivalen.

Diketahui $D=\{x:-7 \leq x \leq 13, x$ bilangan prima $\}$ Relasi pada D didefinisikan sebagai "factor dari".

a. Gambarkan relasi pada $\mathrm{D}$ dengan diagram panah

b. Apakah relasi pada $\mathrm{D}$ adal ah relasi yang ekuivalen? Tunjukanlah!

Gambar 1. Masalah Terkait Tipe Kesalahan A1

Gambar 2 memperlihatkan bahwa mahasiswa belum memahami definisi dari "relasi pada D," sehingga keliru dalam menentukan himpunan kodomainya. Selanjutnya untuk menjawab bagian $b$, mahasiswa sudah mencoba menuliskan definisi relasi ekuivalen, namun masih salah dalam menuliskan arti sifat refleksif, simetris dan transitif, sehingga belum mampu menunjukkan bahwa relasi pada himpunan D merupakan relasi yang ekuivalen atau bukan.

Kesalahan faktual mahasiswa dalam memahami suatu definisi dapat terjadi, karena adanya distorsi definisi, yaitu proses mengubah definisi yang relevan dengan solusi masalah (Schnepper \& McCoy, 2013). Kesalahan pada pemahaman definsi mengindikasikan bahwa mahasiswa kurang memiliki pemahaman yang mendalam tentang suatu konsep, sehingga hal ini dapat mempengaruhi akses seseorang ke matematika yang lebih tinggi (Morgan, 2005; Vinner, 2002). Dengan demikian, penting bagi mahasiswa untuk mengetahui dan memahami definisi atau istilah-istilah matematika.

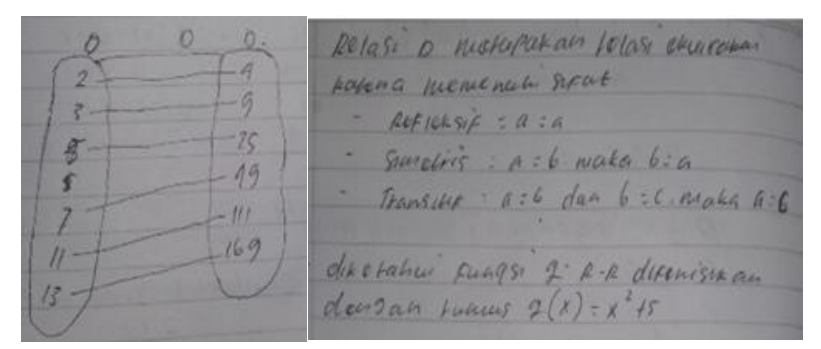




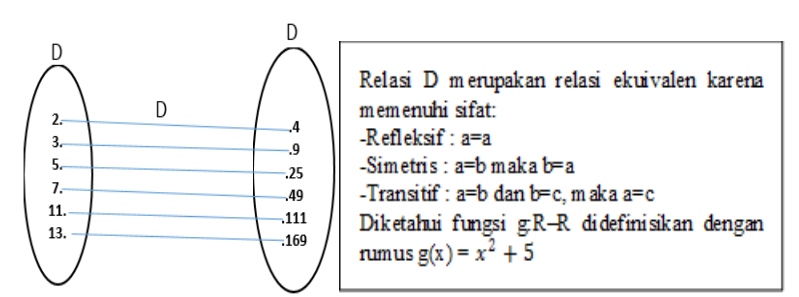

Gambar 2. Kesalahan Fakta Mahasiwa dalam memahami defnisi

Kesalahan selanjutnya yaitu kesalahan dalam memahami gagasan dan prinsip dasar dari suatu konsep (B1) dan Kesalahan memahami hubungan antara ide dan prinsip (B2) dilakukan mahasiswa dalam menyelesaikan masalah pada gambar 3.

\section{Soal:}

Hitunglah luas daerah yang dibatasi oleh kurva: $y=4 x$ dan $y=x^{2}$ dan sketsakan grafiknya!

Gambar 3. Masalah terkait tipe kesalahan B1 dan B2

Kesalahan mahasiswa secara konseptual ini berkaitan dengan menyelesaikan masalah topik integral, yaitu menghitung luas daerah yang dibatasi oleh dua kurva dan mensketsa grafik kedua fungsi tersebut. Kesalahan yang dilakukan mahasiswa, yaitu menentukan titik potong kurva dari kedua fungsi yang diberikan dan kesalahan dalam mensketsa grafik fungsi $y=4 x$.

Menurut peneliti, kesalahan yang dilakukan mahasiswa diakibatkan oleh lemahnya pemahaman prinsip dasar dalam menggambar grafik fungsi dan prinsip dasar dalam menentukan luas daerah yang dibatasi oleh dua kurva dengan pendekatan integral tentu. Selain itu, mahasiswa tersebut juga belum memahami hubungan antara kedua kurva, untuk selanjutnya memperoleh titik potong kedua kurva, sehingga dapat digambarkan luasan daerah yang dicari.

Hasil pekerjaan mahasiswa yang ditunjukkan pada gambar 4 menunjukkan bahwa mahasiswa telah memperoleh nilai absis untuk kedua kurva, namun gagal dalam menentukan nilai ordinatnya, sehingga salah dalam menggambar titik potong kedua kurva. Selanjutnya dalam menentukan luas daerah dari kedua kurva, mahasiswa harus memahami konsep luas dengan pendekatan integral. Kesalahan mahasiswa ini dapat berpengaruh pada pemahaman selanjutnya dalam pembelajaran kalkulus. Menurut Ahmad (2016), dalam menyelesaikan masalah, diperlukan pemahaman yang kuat mengenai menggambar kurva suatu fungsi dan luas, sehingga dapat membantu menghitung luas dalam pendekatan integral dan pemahaman materi selanjutnya seperti menghitung volume benda putar.

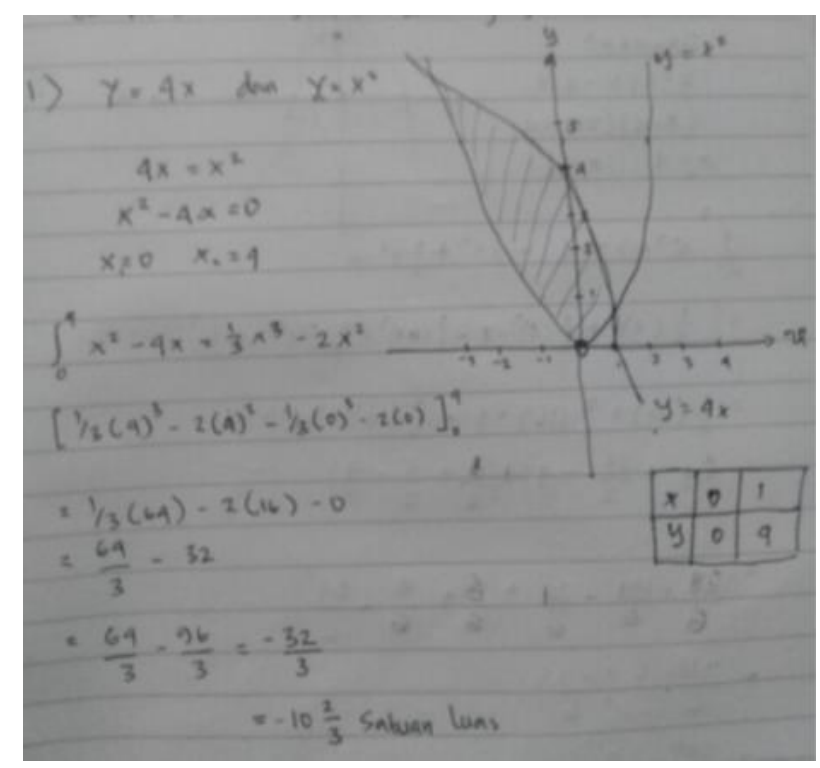

Gambar 4. Hasil Pekerjaan Mahasiswa terkait Tipe Kesalahan B1 dan B2

Tipe kesalahan yang ketiga yaitu kesalahan prosedural. Kesalahan prosedural tipe 1 dan 2 (C1 dan C2) terjadi dalam menerapkan aturan atau rumus langkah demi langkah dan salah dalam melakukan operasi dapat diperhatikan lewat masalah pada gambar 5 yaitu penyelesaian masalah materi vector.

$$
\begin{aligned}
& \text { Soal : } \\
& \text { Jika diketahui } \bar{u}=\left[\begin{array}{l}
2 \\
3 \\
4
\end{array}\right], \bar{v}=\left[\begin{array}{l}
2 \\
2 \\
0
\end{array}\right] \text {, dan } \bar{w}=\left[\begin{array}{c}
2 \\
2 \\
-3
\end{array}\right] \text {, } \\
& \text { tentukanlah: } \\
& \quad \text { a. } \quad|\bar{u}+2 \bar{v}| \\
& \quad \text { b. } \quad(\bar{u} \cdot \bar{w}) \bar{v}-\bar{u}
\end{aligned}
$$

Gambar 5. Masalah terkait tipe kesalahan $\mathrm{C} 1$ dan $\mathrm{C} 2$

Pada Gambar 6 ditunjukan kesalahan yang dilakukan mahasiswa secara prosedural. Penyelesaian masalah bagian a mengharuskan mahasiswa menentukan panjang dari hasil penjumlahan vektor $\mathrm{u}$ dan 2 kali vector v, namun karena tidak memahami masalah maka langkah awal penyelesaian yang dilakukan adalah menentukan panjang dari masing-masing vektor $\mathrm{u}$ dan 2 kali vektor v. Kesalahan pada langkah ini menyebabkan langkah selanjutnya menjadi keliru.

Kesalaahan prosedural lainnya, yaitu kesalahan pada operasi perkalian dua vektor di R3. Berdasarkan hasil pekerjaan mahasiswa pada bagian $b$, mahasiswa salah dalam melakukan perkalian skalar vektor u dan vektor w. Menurut peneliti, keadaan ini disebabkan oleh karena adanya inferensi dari materi sebelumnya tentang operasi perkalian matriks dan mahasiswa 
menganggap perkalian skalar dua vektor ini dapat dikerjakan dengan operasi perkalian matriks. Selain itu, kurangnya pemahaman konsep materi matriks dan vektor membuat mahasiswa dapat saja melakukan kesalahan secara prosedural. Konsep operasi penjumlahan, pengurangan dan perkalian vektor belum dipahami secara baik, sehingga prosedur yang digunakan dalam menyelesaikan masalah memberikan kesimpulan yang salah.

Kesalahan prosedural dapat terjadi saat mahasiswa hanya menghafal rumus dan tidak memahami makna dari konsep yang dipelajari. Hal ini sejalan dengan pendapat Pesek dan Kirshner (2000) yang menyatakan bahwa mempelajari prosedur dengan menghafal sebelum mempelajari konsep dan penerapannya dalam prosedur tersebut akan mengganggu pembelajaran yang bermakna di kemudian hari. Ashlock (2006) mengatakan, pemahaman prosedural terkadang diajarkan tanpa menghubungkan langkah-langkah tersebut dengan ide-ide matematika secara memadai. Dengan demikian, pemahaman prosedural perlu diperhatikan agar dapat meminalkan kesalahan prosedural dan membantu mahasiwa untuk lebih memahami konsep pembelajaran selanjutnya dengan lebih baik.

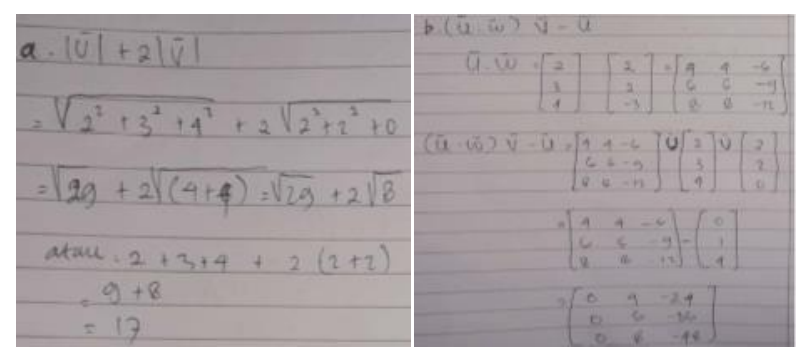

Gambar 6. Kesalahan Prosedural Mahasiswa dalam Menyelesaikan Masalah Topik Vektor

Tipe kesalahan yang terakhir merupakan kesalahan karena kecerobohan. Salah satu kesalahan yang dibuat mahasiswa dalam menyelesaikan masalah topik Himpunan, yaitu karena kurang teliti dalam memberikan alasan terhadap masalah seperti nampak pada gambar 7 . Menurut peneliti, kesalahan yang dilakukan mahasiswa ini terjadi karena kecerobohan dalam mengidentifikasi informasi yang ada pada masalah, sehingga alasan yang dikemukakan kurang tepat.

Soal:

Apakah himpunan-himpunan berikut sama?

Berikan alasanmu!

$$
A=\{\varnothing, 0,1\}, \quad B=\{\{0\}, 1,2\} \quad C=\{\{\varnothing\}, 1,2\}
$$

Gambar 7. Masalah terkait tipe kesalahan D1

Berdasarkan hasil pekerjaan mahasiswa pada gambar 8 terlihat bahwa mahasiswa dapat memberikan alasan yang tepat ketika diberikan tiga buah himpunan dan mahasiswa memberikan alasan dengan memperhatikan hubungan dari anggota dari himpunan $\mathrm{A}$ dan $\mathrm{B}$, himpunan $\mathrm{B}$ dan $\mathrm{C}$ serta himpunan A dan C. Namun, mahasiswa tidak teliti dalam memberikan alasan untuk himpunan $\mathrm{B}$ dan $\mathrm{C}$, karena fokus perhatian mahasiswa hanya terarah pada himpunan kosong, padahal jelas bahwa ada anggota yang tidak sama, yaitu 0 dan 2. Menurut Brown \& Skow (2016), kecerobohan dapat terjadi, karena perhatian mahasiswa terarah pada sesuatu yang lain.

Selanjutnya kesalahan kecerobohan lainnya, yaitu kesalahan karena kurangya waktu dalam mengerjakan soal. Hal ini dialami oleh mahasiswa dalam mengerjakan hampir di setiap masalah yang diberikan. Menurut peneliti, sebagian besar mahasiswa memilih untuk mengerjakan soal yang dianggap lebih mudah terlebih dahulu dan akhirnya mereka kehabisan waktu untuk menyelesaikan jawaban mereka. Pradini, 2019; Rosmaiyadi, 2018; Veloo dkk, 2015 mengatakan manajemen waktu yang kurang baik dalam menyelesaikan soal menjadi salah satu penyebab kesalahan siswa melakukan kecerobohan. Dengan demikian, kesalahan karena kecerobohan ini perlu mendapat perhatian oleh dosen, sehingga dapat memberikan dampak yang positif untuk keberhasilan belajar mahasiswa.

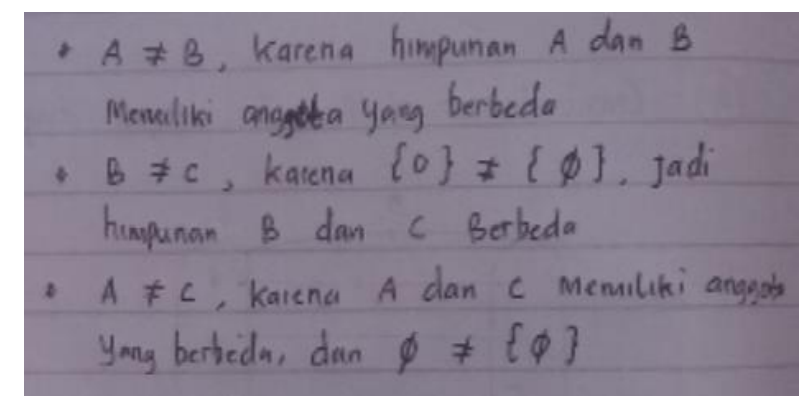

Gambar 8. Hasil pekerjaan mahasiswa terkait penyelesaian masalah tipe D1

\section{Kesimpulan}

Mahasiswa baru Program Studi Pendidikan Matematika FKIP Unpatti melakukan beberapa tipe kesalahan dalam menyelesaikan masalah matematika dasar, yaitu pada materi himpunan, relasi, fungsi, matriks, vektor, limit, turunan dan integral. Kesalahan yang ditemui dalam penelitian ini diklasifikasikan dalam 4 tipe kesalahan, yaitu kesalahan faktual, prosedural, konseptual dan kesalahan karena kecerobohan. Penelitian ini memberikan masukan kepada peneliti selaku dosen Program Studi Pendidikan Matematika terhadap gambaran kesulitan yang dilakukan, sehingga dapat menyusun bahan ajar atau perangkat pembelajaran lainnya yang sesuai dengan 
kebutuhan mahasiswa yang dapat membantu meminimalkan kesalahan mahasiswa di waktu yang akan datang.

\section{Ucapan Terima Kasih}

Peneliti mengucapkan terima kasih kepada pimpinan Fakultas Keguruan dan Ilmu Pendidikan Universitas Pattimura yang telah mendanai penelitian ini dengan Dana PNBP Unpatti di tahun 2020

\section{Daftar Pustaka}

Ahmad, A. M. (2016). Analisis Kesulitan Belajar Matematika Pada Materi Integral Luas Daerah di Bawah Kurva dan Volume Benda Putar. AnNahdhah, 12(23), 159-176.

Ashlock, R. B. (2006). Error patterns in computation: using error patterns to improve instruction 9th Edition (9th ed.; L. A. Montgomery, ed.). Ohio, Columbus: Pearson Prentice Hall.

Brown, J., \& Skow, K. (2016). Mathematics: with Instructor ' $\mathrm{s}$ Guide Table of Contents $\mathrm{n}$ Mathematics: Identifying and Addressing Student Errors.

Hasim, E. (2020). PENERAPAN KURIKULUM MERDEKA BELAJAR PERGURUAN TINGGI DI MASA PANDEMI COVID-19. Prosiding Webinar Magister Pendidikan Dasar Pascasarjana Universitas Negeri Gorontalo “ Pengembangan Profesionalisme Guru Melalui Penulisan Karya Ilmiah Menuju Anak Merdeka Belajar, 68-74. Gorontalo: Universitas Negeri Gorontalo.

Kapur, M. (2014). Productive failure in learning math. Cognitive Science, 38(5), 1008-1022. https://doi.org/10.1111/cogs. 12107

Kesumawati, N. (2008). Pemahaman konsep matematik dalam pembelajaran matematika. Prosiding SeminarNasional Matematika Dan Pendidikan Matematika, Jurusan Pendidikan Matematika Fakultas Matematika Dan Ilmu Pengetahuan Alam Universitas Negeri Yogyakarta, 229-235.

Mataheru, W. 2017. Laporan Kegiatan Matrikulasi. Ambon. Program Studi Pendidikan Matematika FKIP Unpatti.

Mills, G. E., \& Gay, L. R. (2019). Educational Research: Competencies for analysis and application Twelfth Edition. In Pearson Education (Twelfth). United State America: Pearson Education.
Morgan, C. (2005). Word, definitions and concepts in discourses of mathematics, teaching and learning. Language and Education, 19(2), 102116. https://doi.org/10.1080/09500780508668666

Nurhikmayati, I. (2017). Analisis kesulitan belajar mahasiswa pada matakuliah matematika dasar. Theorems, 2(1), 74-85.

Pesek, D. D., \& Kirshner, D. (2000). Interference of instrumental instruction in subsequent relational learning. Journal for Research in Mathematics Education, 31(5), 524-540. https://doi.org/10.2307/749885

Pradini, W. (2019). Analisis kesalahan siswa dalam menyelesaikan soal cerita persamaan linear dua variabel. Pythagoras: Jurnal Pendidikan Matematika, 14(1), 33-45. https://doi.org/10.21831/pg.v14i1.21481

Ratumanan, T. G., \& Laurens, T. (2016). ANALISIS PENGUASAAN OBJEK MATEMATIKA (Kajian pada Lulusan SMA Di Provinsi Maluku). Jurnal Pendidikan Matematika Raflesia, 1(2), $146-154$.

Rosmaiyadi. (2018). Analisis Kesalahan Penyelesaian Soal Aljabar Pada Mahasiswa Program Studi Pendidikan Matematika STKIP Singkawang. Jurnal Pendidikan Matematika, 12(1), 59-70.

Schnepper, L. C., \& McCoy, L. P. (2013). Analysis of Misconceptions in High School Mathematics. Networks: An Online Journal for Teacher Research, 15(1), 625-625. https://doi.org/10.4148/2470-6353.1066

Subanji, \& Nusantara, T. (2013). Karakterisasi kesalahan berpikir siswa dalam mengonstruksi konsep matematika. Jurnal Ilmu Pendidikan, 19(2), 208-217.

Utari, R. S., \& Utami, A. (2019). Kemampuan Pemahaman Konsep Mahasiswa Dalam Mengidentifikasi Penyelesaian Soal Integral Tak Tentu Dan Tentu. Jurnal Pendidikan Matematika, 14(1), 39-50. https://doi.org/10.22342/jpm.14.1.6820.39-50

Veloo, A., Krishnasamy, H. N., \& Wan Abdullah, W. S. (2015). Types of student errors in mathematical symbols, graphs and problem-solving. Asian Social Science, 11(15), 324-334. https://doi.org/10.5539/ass.v11n15p324

Vinner, S. (2002). The role of aesthetics in the teaching and learning of data modelling. In Advanced mathematical thinking (pp. 65-81). https://doi.org/10.1080/09500693.2021.1875514

Zulkardi. 2003. Pendidikan Matematika di Indonesia: Beberapa Permasalahan dan Upaya Penyelesaiannya. Palembang: Universitas Sriwijaya 